\title{
Development of Chorda Tympani Taste Responses in Rat
}

\author{
M.F. FERRELL, C.M. MISTRETTA, AND R.M. BRADLEY \\ Department of Oral Biology, School of Dentistry, University of Michigan, Ann \\ Arbor, Michigan 48109
}

\begin{abstract}
To learn whether neurophysiological taste responses change during structural development of the gustatory system, we recorded from the chorda tympani nerve in rats aged 7 to 92 days after birth. Chemical stimuli applied to the anterior tongue included four monochloride salts, two acids, sucrose, and urea. Responses to all chemicals were obtained as early as 7 days postnatally. Developmental changes in salt, acid, and sucrose responses were observed. Relative to $\mathrm{NaCl}$ and $\mathrm{LiCl}, \mathrm{NH}_{4} \mathrm{Cl}$ and $\mathrm{KCl}$ gradually decrease in effectiveness as taste stimuli; or, relative to $\mathrm{NH}_{4} \mathrm{Cl}$ and $\mathrm{KCl}, \mathrm{NaCl}$ and $\mathrm{LiCl}$ become more effective stimuli. These changes are similar to those observed prenatally and postnatally in sheep. Also, relative to $\mathrm{NaCl}$, citric acid, hydrochloric acid, and sucrose become less effective stimuli; or, $\mathrm{NaCl}$ becomes more effective as a stimulus, relative to these acids and sucrose. The period of most rapid functional change overlaps a period of rapid structural change. It seems most reasonable to hypothesize that the altering taste responses reflect developmental changes in receptor membrane composition. Since the taste system is not programmed to respond in a mature manner from the moment function begins, there is ample opportunity for changing taste experience to influence the developing taste system.
\end{abstract}

Although it has been known for several years that the peripheral taste system of the sheep fetus is neurophysiologically functional for at least the last third of gestation (Bradley and Mistretta, '73a), it is only more recently that developmental changes in taste response characteristics have been described. Changes occur in responses from taste neurons of the solitary tract nucleus in sheep fetuses from about 80 days of gestation to term at 147 days (Mistretta and Bradley, '77, '78; Bradley and Mistretta, ' 80 ). These changes include decreases in response latency, lengthening of the response discharge time, and an increase in number of chemicals that elicit a response. Further, responses to salt stimuli do not develop randomly, but in a specific sequence; taste neurons respond to stimulation of the tongue with $\mathrm{NH}_{4} \mathrm{Cl}$ and $\mathrm{KCl}$ earlier in gestation than to $\mathrm{NaCl}$ and $\mathrm{LiCl}$. A progressive increase in the relative effectiveness of $\mathrm{NaCl}$ and $\mathrm{LiCl}$ as stimuli has also been observed in the peripheral taste system (Bradley and Mistretta, '79).

Maturation of taste function in the sheep is accompanied by structural changes which take place prenatally. Much of the development of this sensory system therefore occurs in an intrauterine environment. To learn whether sim- ilar changes occur in another species with a very different developmental time course, we have studied taste responses in rats aged 7 to 92 days. Whereas structural development of taste buds in the sheep is essentially a prenatal phenomenon, in rats taste buds develop postnatally. Taste buds appear in the fungiform papillae on the rat tongue at about 20 days of gestation, but do not acquire adult morphological characteristics until 2 weeks after birth (Farbman, '65; Mistretta, '72).

We present evidence for changes in neurophysiological responses of the peripheral taste system to stimulation of the developing rat tongue. The changes are in some respects comparable to those reported in sheep for salt and acid responses (Bradley and Mistretta, '80; Mistretta and Bradley, '78, '80). A preliminary report of some of these data has appeared (Ferrell et al., '79), and independently another laboratory has reported similar results (Hill and Almli, '79; Hill and Almli, ' 80 .

\footnotetext{
Address reprint requests to Dr. Charlotte M Mistrelta. Depart ment of Oral Biology. School of Dentistry, Universily of Michigan. Ann Arbor, MI 48109

M.F. Ferrell's present address is Department of Nutrition, College of Agricultural and Environmental Science, University of California, Davis, CA 95616 .
} 


\section{METHODS}

Thirty-five preweaning rats (7-21 days) and 36 weaned rats (22-92 days) were used. Rats aged 7-30 days were anesthetized with intraperitoneal injections of Chloropent, a solution of sodium pentobarbital and chloral hydrate, diluted with physiological saline in a ratio of 1 part Chloropent: 2 parts saline. A dose of 7.5 $\mathrm{ml} / \mathrm{kg}$ body weight was administered with $75 \%$ of the dose injected initially and the remainder, about 10 minutes later. The anesthetized infant rat was placed on a gauze-covered heating pad maintained at $39^{\circ} \mathrm{C}$, and a tracheotomy was performed. To avoid trauma to the oral region, the head was held rigid for dissection by a flat metal bar attached to the forehead with rapidly setting cyanoacrylate glue. Animals older than 30 days were anesthetized with an intraperitoneal injection of sodium pentobarbital (50 $\mathrm{mg} / \mathrm{kg}$ body weight), placed on a heating pad, tracheotomized, and secured in a headholder.

The left chorda tympani nerve was exposed by lateral dissection of the head, cut near its entrance into the tympanic bulla, and then freed to the branch point with the lingual nerve. The nerve was desheathed and placed on a platinum iridium electrode connected to an AC preamplifier, with an indifferent electrode in nearby tissue. Neural activity was analyzed by passing the amplified signal through an AC to DC converter (time constant $=0.5$ second) connected to a rectilinear pen recorder (Beidler, '53). Responses were also monitored on an oscilloscope and audio amplifier. Electrophysiological responses were recorded from the whole chorda tympani nerve during stimulation of the anterior tongue with chemicals.

Stimuli were $0.1 \mathrm{M} \mathrm{NaCl}, \mathrm{LiCl}, \mathrm{KCl}$, and $\mathrm{NH}_{4} \mathrm{Cl}, 0.01 \mathrm{~N} \mathrm{HCl}, 0.0025 \mathrm{M}$ citric acid, $0.5 \mathrm{M}$ sucrose, and $1.0 \mathrm{M}$ urea. All chemicals were dissolved in distilled water and were kept at room temperature during experiments. One milliliter of each stimulus was applied to the anterior tongue using a glass pipette; in rats older than 30 days, $3 \mathrm{ml}$ were applied. After 15-20 seconds the tongue was rinsed with distilled water for at least 30 seconds. The stability of each preparation was monitored by using $0.1 \mathrm{M} \mathrm{NaCl}$ as every third or fourth stimulus.

A response was defined as an increase above baseline of the integrated neural activity, measured in arbitrary chart paper units at 10 seconds following stimulus onset. The response magnitude at 10 seconds provides a measure of the "steady-state" response and avoids including measurement of a tactile component that occurs in the early portion of the response. To eliminate tactile stimulation, chemicals should be applied to the tongue via a flow chamber, but this was not practical in the very young rat pups. Yet the dynamic portion of the response would be of interest for study because this portion varies according to the chemical stimulus in young rats as it does in adults (Pfaffmann, '55).

Since one of our principal goals was to describe a possible change in taste response as a function of age, it was necessary to compare response magnitudes among different animals. Many variables other than age can affect the magnitude of the whole nerve integrated response. For example, response magnitude may alter according to the position of the nerve on the electrode, the length of nerve in air, the extent of neural damage during dissection, the degree to which connective tissue and the neural sheath are removed, and the physiological condition of the experimental animal. There fore, as Beidler ('61) noted several years ago, it is not valid to directly compare absolute response values among animals and the responses from any one animal must be carefully monitored with a standard chemical. For each animal, we calculated a ratio of every response relative to the standard $0.1 \mathrm{M} \mathrm{NaCl}$ response. Thus a response equal to that elicited by stimulating the tongue with $0.1 \mathrm{M} \mathrm{NaCl}$ would have a ratio of 1.0. In other studies $0.1 \mathrm{M} \mathrm{NaCl}$ has also been used as a standard since it is a very effective stimulus when recording from the rat chorda tympani (Beidler, 1953), and there are published data of response ratios for many chemicals relative to $0.1 \mathrm{M} \mathrm{NaCl}$ (Beidler et al., '55; Fishman, '57). Once ratios were calculated for each rat, comparisons could be made among animals.

\section{RESULTS \\ Changes in Order of Stimulus Effectiveness With Age}

Examination of responses from the chorda tympani nerve to stimulation of the tongue with four monochloride salts reveals a marked difference with age. Representative recordings from a young rat (aged 12 days) and an adult rat are shown in Figure 1. At the two ages the order of effectiveness of the monochloride salts in terms of magnitude of elicited response is different. In the young rat the order is $\mathrm{NH}_{4} \mathrm{Cl}$ $>\mathrm{LiCl}>\mathrm{NaCl}>\mathrm{KCl}$, whereas in the adult the order is $\mathrm{LiCl}>\mathrm{NaCl}>\mathrm{NH}_{4} \mathrm{Cl}>\mathrm{KCl}$. This change implies that with increasing age, $\mathrm{NaCl}$ 

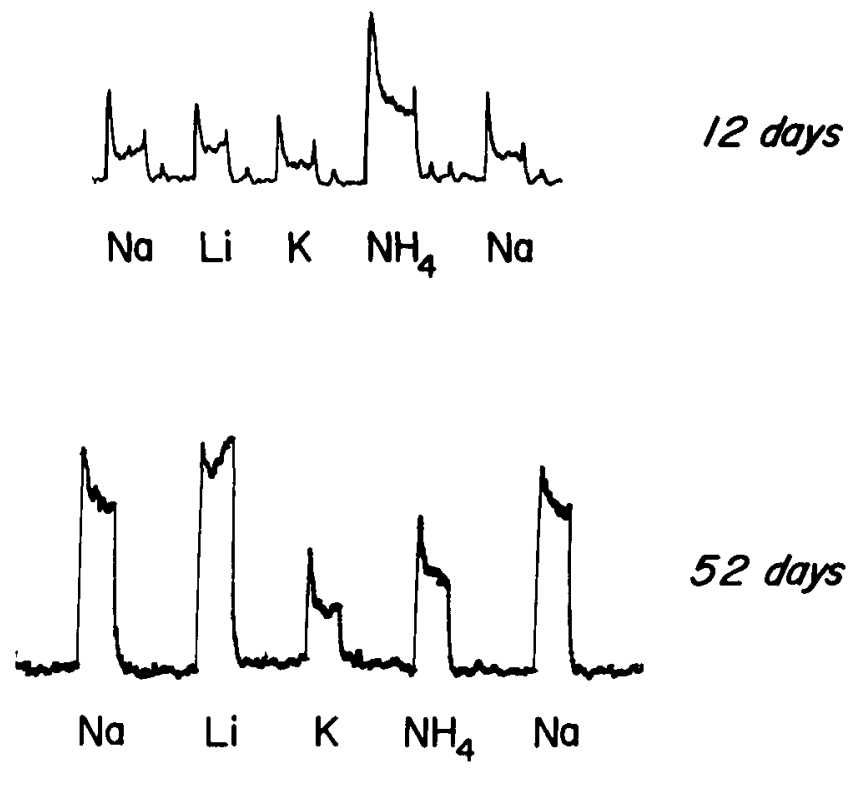

Fig. 1. Integrated records of neural responses from the chorda tympani nerve in a rat aged 12 days (after birth) and an adult rat aged 52 days. Chemical stimuli applied to the anterior tongue were $0.1 \mathrm{M} \mathrm{NaCl}, \mathrm{LiCl}, \mathrm{KCl}$, and $\mathrm{NH}_{4} \mathrm{Cl}$, in the order indicated on the figure. The time mark at the bottom represents 60 seconds. Relative to $\mathrm{NH}_{4} \mathrm{Cl}, \mathrm{NaCl}$ and $\mathrm{LiCl}$ are more effective stimuli in older animals.

and $\mathrm{LiCl}$ become more effective stimuli relative to $\mathrm{NH}_{4} \mathrm{Cl}$. Or, in other words, $\mathrm{NH}_{4} \mathrm{Cl}$ be comes less effective, relative to $\mathrm{NaCl}$ and $\mathrm{LiCl}$. $\mathrm{KCl}$ is the least effective stimulus at both ages.

Changes in order of effectiveness also take place with other stimuli (Fig. 2). In the young rat: $\mathrm{HCl}>$ citric acid $>\mathrm{NaCl}>$ sucrose $>$ urea; and in the adult: $\mathrm{NaCl}>\mathrm{HCL}>$ sucrose $>$ citric acid $>$ urea. The most impressive change is in the increased effectiveness of $\mathrm{NaCl}$ and the marked decrease in effectiveness of citric acid with age. Urea is the least effective stimulus at both ages.

Differences in the time course of responses to individual chemicals are already apparent in young rats. Even as early as 15 postnatal days, the integrated responses to salts and acids rise rapidly to a large peak and then adapt, whereas the sucrose response has a much smaller initial peak (Fig. 2). Such differences in the adult rat were reported several years ago by Pfaffmann ('55).

\section{Changes in Response Ratio With Age}

When ratios of the responses to each chemical, relative to the $0.1 \mathrm{M} \mathrm{NaCl}$ response, are plotted as a function of age, changes in taste function are apparent. The age-related differences in responses to chemical stimulation of the tongue are not sudden, but rather, occur gradually. However, during the first 20 days after birth changes occur very rapidly. These changes are illustrated in Figure 3 for the monochloride salts. Perhaps the most striking curve is that for $\mathrm{NH}_{4} \mathrm{Cl}$, which initially elicits a neural response four times greater than that to $\mathrm{NaCl}$, but within 20 days elicits a response equal to or smaller than $\mathrm{NaCl} . \mathrm{KCl}$ is never more effective than $\mathrm{NaCl}$ as a stimulus, but like $\mathrm{NH}_{4} \mathrm{Cl}$, it decreases in relative effectiveness with age. On the other hand $\mathrm{LiCl}$ and $\mathrm{NaCl}$ do not change in relation to each other.

The response ratios for other stimuli are shown in Figure 4. Both of the acids have response ratios greater than 1.0 in young animals, but less than 1.0 in older animals. Similarly, sucrose decreases in effectiveness relative to $\mathrm{NaCl}$ as a function of age. The response ratios for urea are variable with little significant developmental change. However, this stimulus only elicited a relatively small neural discharge at any age.

Generally, therefore, most chemical stimuli are either more effective than or equal to $\mathrm{NaCl}$ (and $\mathrm{LiCl}$ ) in young rats. During development, $\mathrm{NaCl}$ becomes relatively more effective as a 


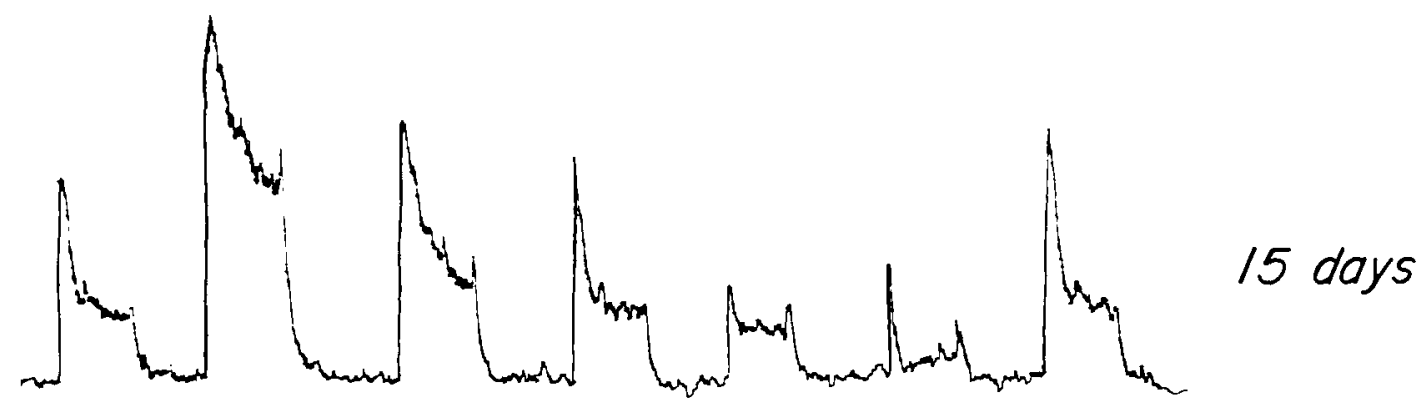

$\mathrm{Na} \quad \mathrm{HCl}$ Citric $\mathrm{Na}$ Suc Urea $\mathrm{Na}$

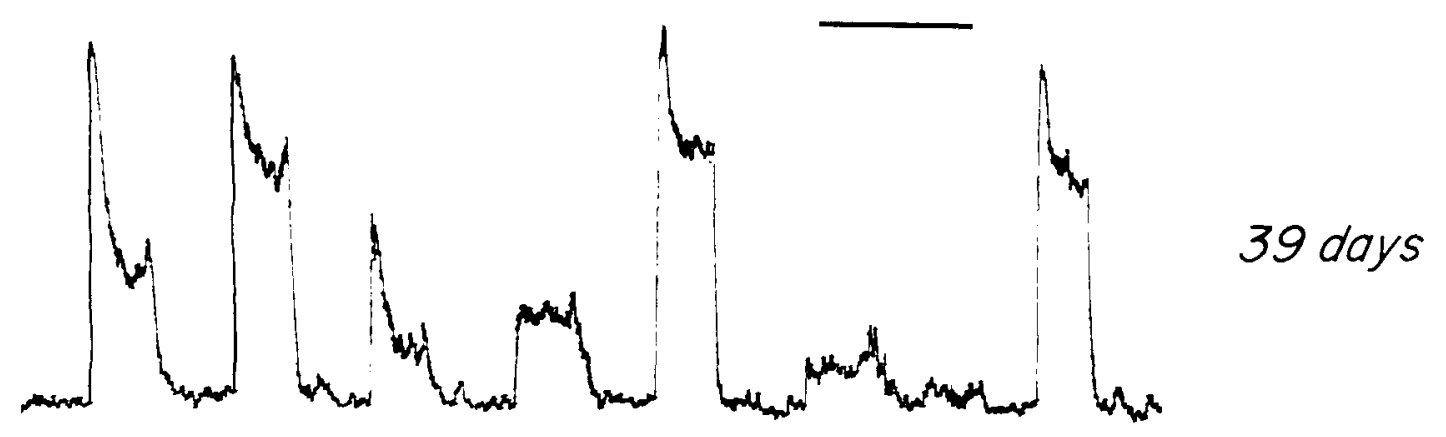

\section{$\mathrm{HCl} \quad \mathrm{Na}$ Citric Suc $\mathrm{Na}$ Urea $\mathrm{Na}$}

Fig. 2. Integrated records of neural responses from the chorda tympani nerve in rats aged 15 and 39 days (after birth). Chemical stimuli applied to the anterior tongue were $0.1 \mathrm{M} \mathrm{NaCl}, 0.01 \mathrm{~N} \mathrm{HCl}, 0.0025 \mathrm{M}$ citric acid, $0.5 \mathrm{M}$ sucrose, and $1.0 \mathrm{M}$ urea. The time mark indicates 60 seconds.

stimulus, or other stimuli become less effective relative to $\mathrm{NaCl}$. With multifiber recording techniques it can only be concluded that chemicals change in stimulating effectiveness relative to each other. Single fiber studies might clarify whether the response to any of these chemicals is relatively constant during development.

The curves for these changes in relation to age are rather similar and a power function fits the data at a highly significant statistical level ( $\mathrm{P}<0.002$, Figs. 3, 4). Other functions, including exponential and hyperbolic, also describe the data for each chemical at a significant level. However, without a sound biological reason for selecting one function or another, the curve-fitting procedure only serves to emphasize that the changes in chemical responsiveness occur relatively rapidly during the first 3 weeks after birth and more slowly thereafter as ratios similar to those in the adult are attained. Therefore we do not intend to conclude that an exponential function provides the best fit for each curve, but rather tha it adequately describes all of these curves.

\section{DISCUSSION}

Neurophysiological responses recorded from taste receptors in immature rats are not the same as those recorded from adults. Salt, acid, and sucrose responses alter relative to each other during development, changing rapidly at first and gradually after about 3 postnatal weeks. Using the same salt stimuli at higher 

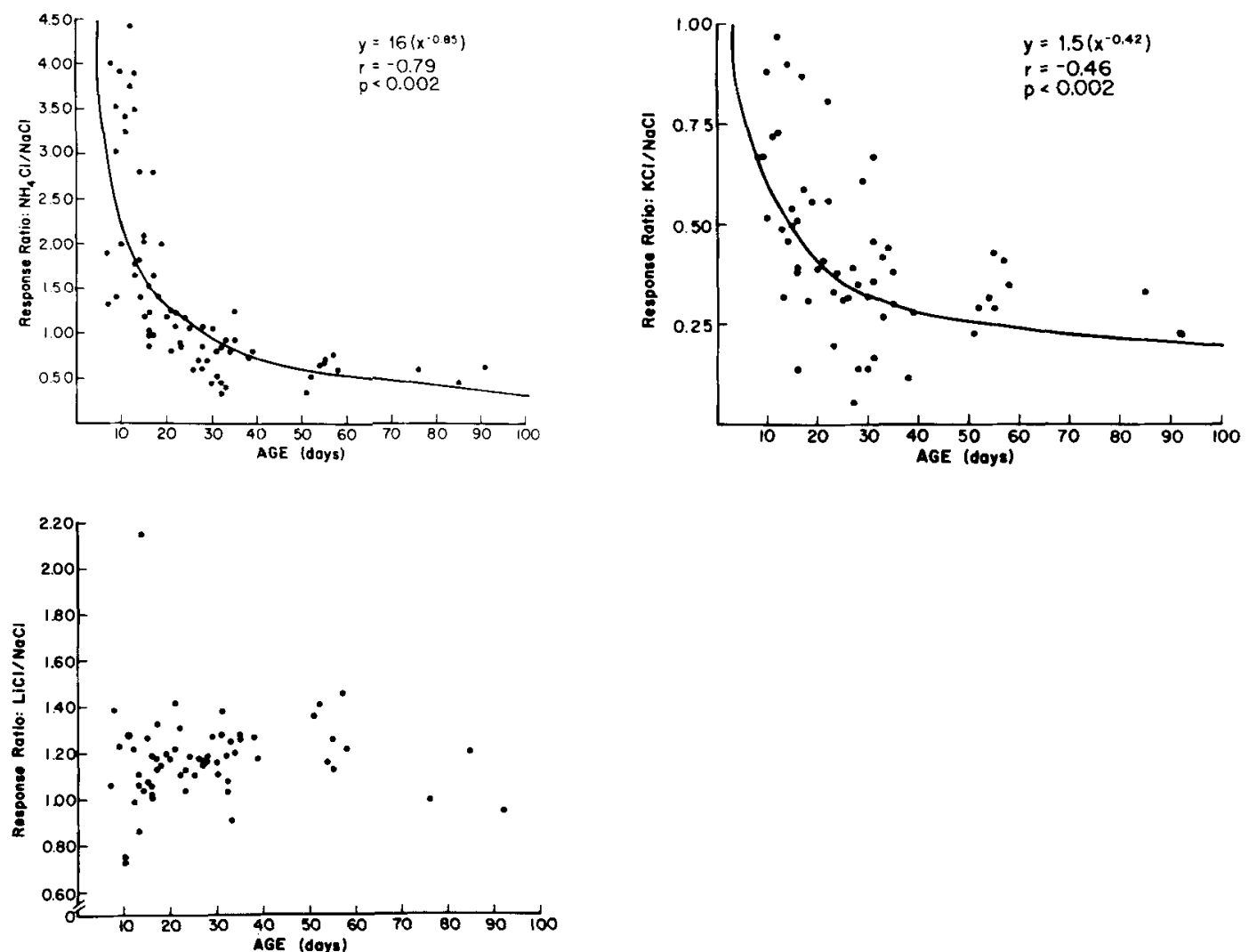

Fig. 3. Ratios of the responses to $0.1 \mathrm{M} \mathrm{NH}_{4} \mathrm{Cl} / 0.1 \mathrm{M} \mathrm{NaCl}$, to $0.1 \mathrm{M} \mathrm{KCl} / 0.1 \mathrm{M} \mathrm{NaCl}$, and to $0.1 \mathrm{M} \mathrm{LiCl} / 0.1 \mathrm{M} \mathrm{NaCl}$, plotted as a function of age. Thus each data point represents the response to a monochloride salt, relative to the $\mathrm{NaCl}$ response, in one animal. Responses to $\mathrm{NH}_{4} \mathrm{Cl}$ and $\mathrm{KCl}$ change during development whereas the response to $\mathrm{LiCl}$ remains the same relative to $\mathrm{NaCl}$. The changes in salt taste responses are gradual and are adequately described by a power function, indicated in each figure.

concentrations (0.5 M), Hill and Almli ( 79 ; '80) have independently reached similar conclu. sions about developing salt responses in rat. These developmental changes therefore apply over a wide dynamic range of receptor responses.

There are a number of hypotheses about possible related phenomena, both extrinsic and intrinsic to the taste system, that may correlate with functional development. For example, it is possible that these changes relate to alterations in the oral environment as the developing rat progresses from milk to a solid diet. But since the transition in taste response characteristics begins well before veaning takes place, it is unlikely that the changes are caused by diet. Changes in salivary composition also occur postnatally in the rat (Schneyer et al., '72). Secretion can be obtained from the salivary glands soon after birth. However, from about 15 days postnatally to 49 days of age, [Na] progressively increases in maximally stimulated parotid saliva while $[\mathrm{K}]$ decreases. Although there are no significant developmental differences in [Na] and [K] in submaxillary saliva, the parotid changes would influence overall salivary composition. Interestingly, as salivary [Na] increases and [K] decreases, $\mathrm{NaCl}$ is becoming a more effective taste stimulus relative to $\mathrm{KCl}$ (Fig. 3). These parallel changes may be unrelated, or perhaps additional $\mathrm{Na}$ ions in the oral environment provide increasing stimulation for the taste system and thereby contribute to increased responsiveness to this cation.

Since similar changes in responsiveness to monochloride salts take place during prenatal development in the sheep, factors extrinsic to the taste system seem less likely to relate directly to the observed taste changes. But 

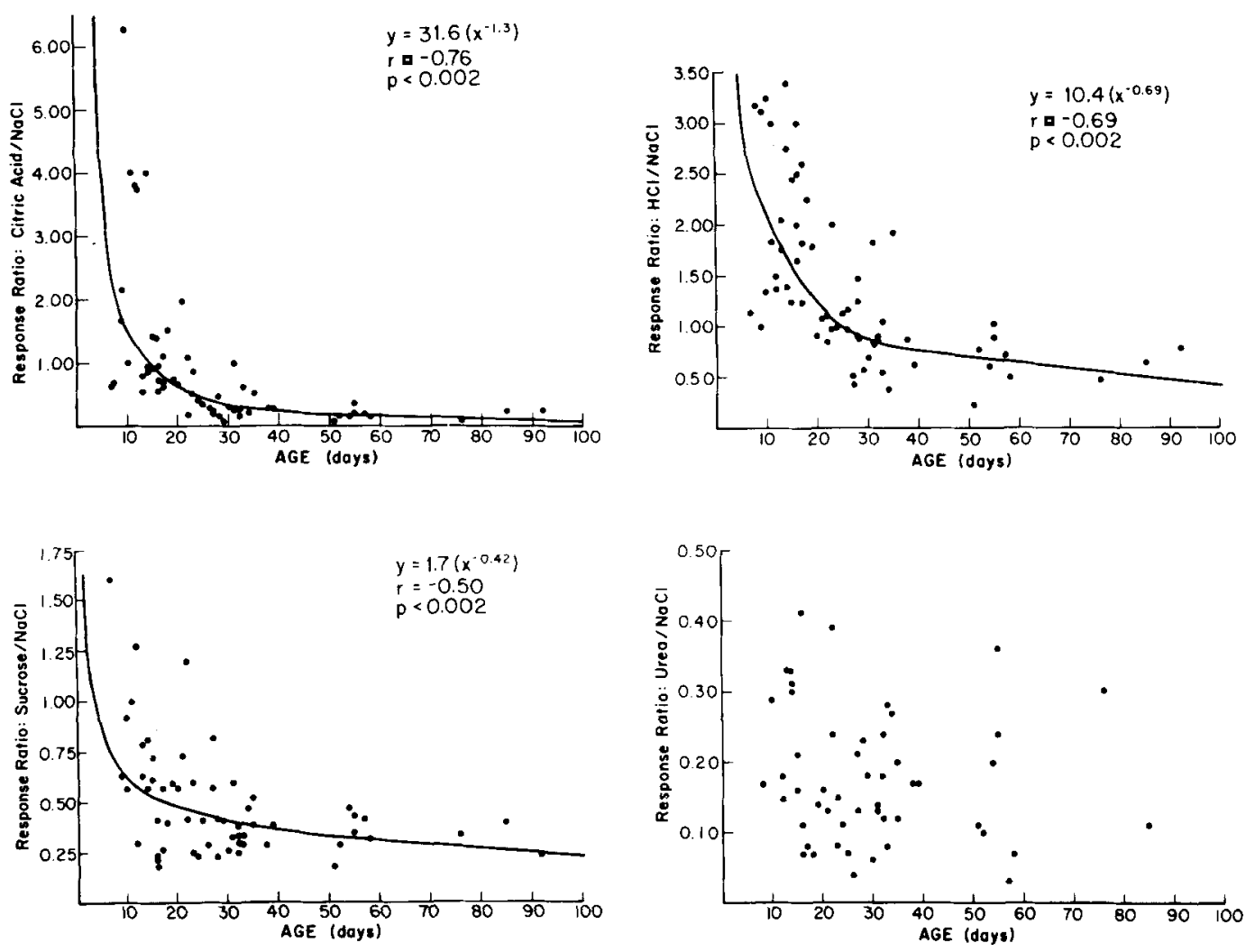

Fig. 4. Ratios of responses to $0.0025 \mathrm{M}$ citric acid/0.1 M NaCl, to $0.01 \mathrm{~N} \mathrm{HCl} / 0.1 \mathrm{M} \mathrm{NaCl}$, to $0.5 \mathrm{M}$ sucrose/0.1 M NaCl, and to $1.0 \mathrm{M}$ urea/0.1 M NaCl, plotted as a function of age. Each data point represents the relative response ratio for one animal. Responses to citric acid, $\mathrm{HCl}$, and sucrose change during development, whereas the response to urea remains the same relative to $\mathrm{NaCl}$. The changes in acid and sucrose responses are gradual and are adequately described by a power function, indicated in each figure.

there are no data on salivary composition in fetal sheep, and it now appears that alterations in the ovine taste system continue postnatally (Mistretta and Bradley, '80). The potential importance of salivary correlates should therefore not be ignored. Interestingly, $[\mathrm{Na}] d e-$ creases and $[\mathrm{K}]$ increases in amniotic fluid during gestation in the sheep (Mellor and Slater, 71). The changes are opposite to those reported in rat saliva, and amniotic fluid is swallowed by the sheep fetus and therefore provides stimulation for the taste system (Bradley and Mistretta, '73b). While the oral environment may have some influence on the developing taste system, there is not a readily apparent, simple relation. Consideration of inherent characteristics of the sense of taste during development may be more fruitful in understanding functional alterations.
There are obvious structural changes in the developing taste system that may relate to functional taste differences. Light microscopic studies of rat taste buds have shown that structural development begins shortly before birth but is still not complete at 12 days after birth (Mistretta, '72). Since the taste pore is a channel that provides direct communication between the taste bud cells and the oral cavity, it may be an important indicator of structural maturation. Only $75 \%$ of the taste pores are apparently open at 12 days after birth in the rat (Mistretta, '72). Therefore, structural maturation of at least some taste buds continues beyond 2 weeks. It is not apparent that an increasing number of open taste pores could account for a change in relative taste responses during development. A developmental increase in open pores could, though, contribute 
to an increase in overall signal to noise ratio in the taste system. Unfortunately we know nothing about detailed development of the taste pore region which could provide further insight into structural-functional relations.

Farbman ('65) observed that at 7 days after birth there are no typical "type II" cells present in the rat taste bud and no taste pore is apparent. Several type I cells are present and these possess microvilli at their apices. By 12 days all cell types are observed, as is a taste pore. It would be interesting to know if more than one type of microvillus is present at 12 days or if there is further development of the microvilli. At least three types of microvilli have been described in the foliate taste bud of the adult rabbit (Jahnke and Baur, '79), and these microvilli may interact differently with chemical stimuli.

Although we lack details of structural development, clearly functional and anatomical maturation of the peripheral taste system are taking place at approximately the same time. The period of rapid functional change overlaps with that of rapid structural change. Therefore the taste system does not begin to function only after structural maturation is complete. This is not only true for the rat, but also for the sheep (Bradley and Mistretta, '80).

The developmental changes recorded in rat whole nerve taste responses must reflect changes in single fiber discharges. To alter the relative magnitude of the whole nerve responses there must be an overall change in frequency of action potentials in the fibers, or in the number of fibers responding. Single fiber responses of course must reflect response properties of the taste cells and ultimately the receptor membranes. It is most reasonable to hypothesize that changing taste response characteristics reflect developmental changes in receptor membrane composition. Developmental changes in membranes in other systems have been shown to relate to functional alterations in the membranes (Kapitulnik et al., '79; Kutchai et al., '76). Our observations on the rat taste system demonstrate that changes occur in responses to salts, acids, and sucrose. Therefore, extensive developmental changes in membrane composition may have to occur to account for altered responses to such a broad range of chemicals.

Since the relative stimulating effectiveness of $\mathrm{NaCl}$ and $\mathrm{LiCl}$ does not change during development, $\mathrm{NaCl}$ and $\mathrm{LiCl}$ are grouped as similar stimuli with perhaps similar response mechanisms as compared with either $\mathrm{NH}_{4} \mathrm{Cl}$ or $\mathrm{KCl}$.
Such a partition of $\mathrm{NaCl} / \mathrm{LiCl}$ versus $\mathrm{NH}_{4} \mathrm{Cl}$ or $\mathrm{KCl}$ is not new in taste electrophysiology and behavior. Other investigators have demonstrated that $\mathrm{NH}_{4} \mathrm{Cl}$ and $\mathrm{KCl}$ elicit more similar responses and may have other taste components in addition to salty for the rat, whereas $\mathrm{NaCl}$ and $\mathrm{LiCl}$ taste more alike and elicit similar responses (Doetsch and Erickson, '70; Morrison, '67; Scott and Erickson, '71; Smith and Frank, '72).

Although the relative responses to four monochloride salts and other chemicals alter during development, it is important to note that soon after birth the rat's gustatory system is already responding to many stimuli. Assuming that the peripheral nerve activity reaches central nervous system relays, the rat should be able to perceive these chemicals. Hall ('79) has recently found that rat pups as young as 1 day after birth ingest varying amounts of chemical stimuli and suggests that the sense of taste plays a primary role in the discrimination among stimuli.

It is difficult to determine what effect the observed changes in relative neural responsiveness to stimuli may have on behavioral responses in the developing rat. Perhaps the low level of neural activity in response to stimulation of the tongue with $\mathrm{NaCl}$ in very young rats does not cross immature central nervous system synapses, whereas the greater activity in response to $\mathrm{NH}_{4} \mathrm{Cl}$ does reach the central nervous system. In this case, the younger rat may not respond behaviorally to low concentrations of $\mathrm{NaCl}$ at all. Or perhaps some neural responses to $\mathrm{NaCl}$ stimulation reach the central nervous system at all ages, but increase in magnitude during development. Whichever alternative is correct, the neurophysiological data suggest that taste perception may also change with age. Since the taste system is not programmed to respond in a mature manner from the moment function begins, there is ample opportunity for changing taste experience to influence the developing taste system.

\section{ACKNOWLEDGMENTS}

This research was supported by N.I.H. Postdoctoral Fellowship \#DE05154 to M.F.F., N.S.F., BNS grant 77-09920 to R.M.B. and C.M.M., and N.I.H., N.I.D.R. Research Career Dev. Award \#DE00066 to C.M.M.

\section{LITERATURE CITED}

Beidler, L.M. (1953) Properties of chemoreceptors of tongue of rat. J. Neurophysiol. 16:595-607. 
Beidler, L.M. (1961) Taste receptor stimulation. Progr. Biophys. Biophys. Chem. 12:107-151.

Beidler, L.M., I.Y. Fishman, and C.W. Hardiman (1955) Species differences in taste responses. Am. J. Physiol. 181:235-239.

Bradley, R.M., and C.M. Mistretta (1973a) The gustatory sense in foetal sheep during the last third of gestation. $J$. Physiol. (Lond.) 231:271-282.

Bradley, R.M., and C.M. Mistretta (1973b) Swallowing in fetal sheep. Science 179:1016-1017.

Bradley, R.M., and C.M. Mistretta (1979) Changes in taste responses from sheep chorda tympani nerve during development. Soc. Neurosci. Abstr. 5:125.

Bradley, R.M., and C.M. Mistretta (1980) Developmental changes in neurophysiological taste responses from the medulla in sheep. Brain Res. 191:21-34.

Doetsch, G.S., and R.P. Erickson (1970) Synaptic processing of taste quality information in the nucleus tractus solitarius of the rat. J. Neurophysiol. 33:490-507.

Farbman, A.I. (1965) Electron microscope study of the developing taste bud in rat fungiform papilla. Dev. Biol. 11:110-135.

Ferrell, F., R.M. Bradley, C.M. Mistretta, and K. Miklossy (1979) Developmental changes in neural taste responses in postnatal rats. Soc. Neurosci. Abstr. 5:127.

Fishman, I.Y. (1957) Single fiber gustatory impulses in rat and hamster. J. Cell. Comp. Physiol. 49:319-334.

Hall, W.G. (1979) The ontogeny of feeding in rats: I. Ingestive and behavioral responses to oral infusions. J. Comp. Physiol. Psychol. 93:977-1000.

Hill, D.L., and C.R. Almli (1980) Ontogeny of chorda tympani nerve responses to gustatory stimuli in the rat. Brain Res. 197:27-38.

Hill, D.L., and C.R. Almli (in press) Ontogeny of chorda tympani nerve responses to gustatory stimuli in the rat. Brain Res.

Jahnke, K., and P. Baur (1979) Freeze-fracture study of taste bud pores in the foliate papillae of the rabbit. Cell Tissue Res. 200:245-256.
Kapitulnik, J., M. Tshershedsky, and Y. Barenholz (1979) Fluidity of the rat liver microsomal membrane: Increase at birth. Science 206:843-844.

Kutchai, H., Y. Barenholz, T.F. Ross, and D.E. Wermer (1976) Developmental changes in plasma membrane fluidity in chick embryo heart. Biochem. Biophys. Acta 436: 101-112.

Mellor, D.J., and J.S. Slater (1971) Daily changes in amniotic and allantoic fluid during the last three months of pregnancy in conscious, unstressed ewes, with catheters in their foetal fluid sacs. J. Physiol. (Lond.) 217:573-604.

Mistretta, C.M. (1972) Topographical and histological study of the developing rat tongue, palate and taste buds. In J.F. Bosma (ed) Third Symposium on Oral Sensation and Perception: The Mouth of the Infant. Springfield: Thomas, pp. 163-187.

Mistretta, C.M. and R.M. Bradley (1977) Maturation of CNS taste responses during fetal development. Ann. Rech. Vet. 8:495-496.

Mistretta, C.M. and R.M. Bradley (1978) Taste responses in sheep medulla: Changes during development. Science 202:535-537.

Mistretta, C.M., and R.M. Bradley (1980) Ontogenesis of salt taste responses in sheep. Proceedings of the Seventh International Symposium on Olfaction and Taste. London: IRL Press, p. 222.

Morrison, G.R. (1967) Behavioral response patterns to salt stimuli in the rat. Canad. J. Psychol./Rev. Canad. Psychol. 21:141-152

Pfaffmann, C. (1955) Gustatory nerve impulses in rat, cat and rabbitt. J. Neurophysiol. 18:429-440.

Schneyer, L.H., J.A. Young, and C.A. Schneyer (1972) Salivary secretion of electrolytes. Physiol. Rev. 52:720-777.

Scott, T.R., and R.P. Erickson (1971) Synaptic processing of taste-quality information in thalamus of the rat. $\mathrm{J}$. Neurophysiol. 34:868-884.

Smith, D.V., and M. Frank (1972) Cross adaptation batween salts in the chorda tympani nerve of the rat. Physiol. Behav. 8:213-220. 